\title{
Mpambu Nzila: José Bedia at the Crossroads
}

\author{
Alan West-Durán
}

check for updates

Citation: West-Durán, Alan. 2021. Mpambu Nzila: José Bedia at the Crossroads. Religions 12: 172. https://doi.org/10.3390/rel12030172

Academic Editor:

Malgorzata Oleszkiewicz-Peralba

Received: 17 January 2021

Accepted: 26 February 2021

Published: 6 March 2021

Publisher's Note: MDPI stays neutral with regard to jurisdictional claims in published maps and institutional affiliations.

Copyright: (C) 2021 by the author. Licensee MDPI, Basel, Switzerland. This article is an open access article distributed under the terms and conditions of the Creative Commons Attribution (CC BY) license (https:/ / creativecommons.org/licenses/by/ $4.0 /)$.
Department of Cultures, Societies \& Global Studies, Northeastern University, Boston, MA 02115, USA; awestduran@gmail.com

\begin{abstract}
The article draws on the Kongo term mpambu nzila of crossroads, that equally signifies altar, to discuss the paintings and drawings of Cuban-born artist José Bedia. He is a practitioner of Palo Briyumba, a syncretic Afro-Cuban religion that combines Kongo religious beliefs, Regla de Ocha, Spiritism, and Catholicism. The article examines six works by the artist from 1984 to 1999 and how Bedia represents Palo in his art. Additionally, the centrality of the nganga (a cauldron that paleros use to work for and protect them) is discussed historically, philosophically, and religiously as a physical and spiritual embodiment of the crossroads. Bedia's work is also analyzed using the Sankofa bird as metaphor (of flying forward and looking back) and as an example of the West African notion of coolness. The article also examines Palo as a de-colonial way of knowing and ends with the crossroads through the example of Lucero Mundo (Elegguá).
\end{abstract}

Keywords: mpambu nzila; crossroads; Regla de Palo; nganga; Sankofa; Regla de Ocha; orisha; mpungu; anti-colonial knowledge; spiritual knowledge; coolness; Sarabanda (Oggún); Pata Llaga (Babalú-Ayé); Lucero Mundo (Elegguá)

Altars are spaces of sacrifice, prayer, devotion, and, more importantly, the imagination. They are crossroads, gateways of communication between humans, nature, and the divine. When we confront the work of Cuban-born artist José Bedia (1959-), this gateway reveals a richly displayed unique universe that is also an inquiry into spirituality, identity, migration, the plight of Cuba, militarism, alternative forms of knowledge, and hidden histories. Most of Bedia's oeuvre does not visually resemble an altar, but the idea of the crossroads as spiritual presence is central to his work.

R.F. Thompson reminds us that "[i]n the Kongo imagination, the place where two paths cross is an automatic point for sacrifice and prayer. The crossroads is a classic Kongo altar, reverberating, ultimately, all to one of the primordial images of the Mississippi Delta blues. The operative term, "mpambu nzila," a phrase variously translated in the Ki-Kongo dictionary as "crossing of paths, crossing, ramification branch, bifurcation, a point of reunion, a point of separation" (Thompson 1993, p. 29). To visualize the altar as a crossroads helps us understand the complex imagery of Bedia's work. Bedia is a practicing palero, an Afro-Cuban religion with deep Kongo roots, as well as a member of the Native American Church. For reasons of length and simplicity I will concentrate on the Palo (and Kongo) influences in Bedia's work.

José Bedia was born and raised in Havana to a middle-class family. He studied at the Instituto Superior de Arte (1981) and participated in a collective exhibition known as Volumen I (1981), which launched the careers of many contemporary Cuban artists such as Flavio Garciandía, Tomás Sánchez, Ricardo Rodríguez Brey, Rogelio López Marín (Gory), and Leandro Soto, among others. By 1982, he had already had his second solo show, remarkable for a 23-year-old artist. In 1983, he became a Palo initiate, an event that would indelibly shape his life both spiritually and artistically.

Palo is considered one of the major Afro-Cuban religious manifestations, along with Regla de Ocha (santería), Abakuá, as well as Arará and Vudú. There are different manifestations of Palo, but I will focus on Palo Briyumba, since Bedia is a briyumbero. Palo 
Briyumba mixes elements of Mayombe (known as the "purest" form), with elements of Ocha. The other variants of Palo are known as Mayombe, Kimbisa, and Shamalongo. The most predominant of Afro-Cuban religious practices in Cuba is known as Regla de Ocha or santería. Like Palo, they are both monotheistic religions, with a belief in intermediary spirits, known as orishas in Ocha and Mpungus in Palo. Both are religions of initiation; in Ocha you are initiated into a specific orisha (tutelary spirit), in Palo you are initiated into an "nganga," a receptacle or cauldron that contains the spirit of a dead person (along with different natural substances that include plants, trees, earth, water, blood, animals, and insects) that is made to work on your behalf. Both religions emphasize the importance of ancestral spirits, both believe in spirit possession, and sacrifice, some animal.

One of Bedia's early pieces after initiation is titled "Sarabanda" (1984). (See reproduction in (Bettelheim and Berlo 2012, p. 44)). It shows a figure, presumably either Bedia or an archetype of a Sarabanda (Zarabanda) which is a "fundamento" of briyumberos, and an important mpungu. Sarabanda is Bedia's "mpungu" and is linked to Oggún in Regla de Ocha. A piece done on charcoal and paper, it references his own initiation. At the bottom, aside from having written Sarabanda's name, we see a nganga on the left and an anvil on the right with a horseshoe on top. The large figure, both Sarabanda and perhaps Bedia himself as incarnation of the mpungu, dominates the drawing itself. The left hand holds a hammer, the right a machete, and each wrist has small chain attached to it, all objects associated with Sarabanda, who is linked to metal objects, weapons, tools, etc. Also, another chain is worn around the waist and an initiation chain (known as "collar de muerto" or "collar de bandera"; necklace of the dead or flag necklace) is strung diagonally across the chest, with the proper attributes. The marks on the body suggest the "rayamiento" (incisions on the body that draw blood) that occurs to palo acolytes as they are initiated. In the background, we see a shower of knives flying through the air almost like metallic beams of light. Interestingly, the knives point away from the figure, as if emanating from the figure itself. The figure is typical of those in Bedia's work, especially the head, almost always in profile with a pointy nose and an almost triangular jaw, possibly alluding to ritual situations where an initiate enters a supernatural realm that is more archetypical than individual.

In that same year Bedia did a triptych that shows the "caldero" (or receptacle) that is empty, a second one showing the different elements going into the making of the nganga and a third with the "prenda" already made and consecrated. All are done with pencil and charcoal on paper and are 30" $\times 20^{\prime \prime}$. See reproduction in (Bettelheim and Berlo 2012, pp. 46-47). The first drawing is plain, almost minimalist, showing the receptacle resting on the ground and surrounded by empty space, except a number 1 in the top left corner. The second has over a hundred objects hurling towards the receptacle, but still in mid-air, as if the nganga was a large magnet bringing to its depths sticks or branches, knives, machetes, other metal objects, herbs, dirt, blood, water, sugar cane, birds, insects, feathers, a snake, bones and a human skull. The upper left part of the painting has a number 2 . The third shows the nganga prepared and in working order, and we see some of the objects in it partially revealed: a machete, an "mpaka" (used in divination), different palos, and the skull. To the left is a lit candle, to the right a bottle, presumably containing malafo, or aguardiente, used for spiritual cleansing. In the foreground we see a snake (majá) and a turtle. The snake is an important and sacred animal and in Palo they work for good and are used to ward off misfortune or evil. Turtles are used for cleansing, for problems of impotence or mental strain, and fertility. Above we have the moon, the morning star; in the upper left-hand corner the number 3 . The moon is like a godmother for mayomberos, and the strength and vibrations of the moon need to be perceived by initiates. Initiations are usually done under a full or new moon. "Sarabanda" and this triptych can be seen as Bedia's introduction for his viewers to the spiritual environment of Palo.

The title to the third piece in the triptych is "The Iron Pot: A Compendium of the World in Miniature." This recalls the words of an informant of Lydia Cabrera who said, "A prenda is like a little world unto its own and it is through it that you gain power. For 
this reason the ngangulero fills his cauldron with all kinds of spirits: within it he has the cemetery, the bush (el monte), the river, the sea, lightning, the whirlwind, the sun, the moon, the stars." (Cabrera [1954] 1992, p. 131) The prenda is central to the religion and Bedia's work references the nganga, either directly or indirectly in many of his paintings. In one of his most famous pieces, from 1999 , done on acrylic and canvas $(8 \times 12 \mathrm{ft})$, the painting is a nganga done in black with the interior done in white and yellow. See reproduction in (Pascual Castillo 2007, p. 77) It is titled "Nkili, Fiongo, Mbele, Chamba, Malafo, Mbua" (Air, Anvil, Knife, Sacred Drink, Firewater, Dog). The painting is like an X-ray of what is inside the nganga. The top features the different palos, metal objects and a human skull. On the skull we find a palo "firma," or sacred signature, which relates to the placement of the nganga with the cross signifying the spiritual power of Nsambi (God) working within the prenda. The second layer contains the "nkili" (air) on the left and the "fiongo" (anvil) on the right and between them a crucifix on a three-step pedestal. In the background are several bursts of light connected by thin lines that evoke the spiritist influences in Palo, where positive spirits are linked to light, and also refer to Lucero, depicted as the guiding light of a prenda. These bursts of light are depicted at all the different layers in the painting. The third layer has the "mbele" (knife, hatchet, machete), and beneath it is a "garabato" ("mombala," a ritual cane) and below it two bottles, one labeled "chamba," the other "malafo." Chamba is a liquid that is sprayed or poured into the nganga to strengthen its powers, and also consumed by initiates. Malafo is a dry wine used for ritual purposes. Between the two bottles is a half-moon with a face in silhouette facing the "garabato" above it. The fourth layer is six different plants, reminding us of the healing properties of the herbs and the role they play in Palo. The bottom level has five birds on each side with a dog ("mbua") in the middle. Birds are used for different ritual purposes ranging from the woodpecker and the owl to the "toti" (Cuban blackbird) and the vulture. The spirit within the nganga is often referred to as the "perro nganga," signaling that the spirit within the nganga is an obedient, dog-like presence that must follow the wishes of the nganga's owner. The nganga has an outer rim with six head silhouettes blowing out and another four blowing in towards the prenda. These silhouetted heads allude to Nsambi's blowing into the ear of humans and imbue them with both a soul and intelligence.

This work by Bedia visually recreates the visible and invisible dimensions of Palo: the artist represents the microcosm of the universe, from the presiding human skull at the top flanked by many metal objects (as well as a goat and a rooster) to the four elements, sacrificial offerings, the plant world, the animal realm (the dog and the birds) as well as the world of the spirits and of the dead. The nganga works on the palero's behalf, both defending him/her, and making them thrive in life's endeavors. The nganga is perhaps the over-arching symbol in Bedia's work even though many of his pieces are not focused on the prenda and it is equally important as to how he sees creativity. He often refers to his art-he has often suggested that he doesn't consider himself an artist in the Western sense-as "labor, trabajo" (labor and work). In this he also echoes the characteristics of the nganga because the nganga is made to work for its owner. It is spiritual work that also works the spirit. In this regard, Bedia's art despite being "deliberately, dissident, and rebellious" (Hernández 2011, p. 138) is not an avant-gardist or revolutionary artist. Hernández calls him somewhat "retrograde, a traditionalist." He continues,

And that calls for an immediate explanation to prevent anybody from making an interpretation of this as something negative, or even reactionary. Even though his works make a beeline into the future, the fact of the matter is that Bedia has spent most of his life looking back, looking to the past, to traditions as old as the world, traditions that still have a lot of contributions to make to our unbalanced and incomplete contemporariness. Or more exactly, looking back and to the sides since a great part of that past is still a part of the present for many a society ... His entire work has been an attempt to pick up the pieces of those destructions and forgetting or what is overlooked, and stitch them back together, as if it were a huge jigsaw puzzle, and come up with a new, recycled image of wisdom, 
creativity and beauty of all these peoples and cultures. His aesthetics could be graphically summed up by one of the best-known symbols (adinkras) of Akan culture-Ghana's Ashanti population-that represents a bird called Sankofa that looks back as it flies straight ahead. This summarizes the respect needed as to what we owe to the past, and to the work of our ancestors, during our life course. A past which is definitely selective, because we're not the children of just "anybody" or of "everybody", but of a particular family, a particular people, or a particular culture. In Bedia's case, we know all too well who is part of his lineage and to whom he feels indebted. (Hernández 2011, p. 138)

This notion of looking back and to the sides while being very much engaged with contemporary concerns is what allows us to avoid the usual binaries about Bedia's art in terms of tradition and modernity, civilization and "primitiveness," reason and intuition, science and religion. Hernandez's Sankofa bird metaphor is apt for describing the artist's learning from the past in order to face the future.

This ability to move forward and look back is linked to what Thompson refers to as coolness, a notion common to many West and Central African cultures and languages. It is associated with the idea of composure, the ability to gracefully maintain your equanimity under pressure, of calming passions in situations that can lead to discord and even violence. Thompson further elaborates: "Manifest within this philosophy of the cool is the belief that the purer, the cooler a person becomes, the more ancestral he becomes. In other words, mastery of self enables a person to transcend time and elude preoccupation. He or she can concentrate upon truly important matters of social balance and aesthetic substance, creative matters, full of motion and brilliance" (Thompson 2011, p. 16). The Sankofa bird metaphor is one of "transcending time" because one becomes better equipped to deal with the present by becoming more ancestral.

This learning from the past is also linked to the de-colonizing element of his work, overtly seen in a work like "Mundele Quiere Saber" (1995), where he references anthropologist Emil Torday, who did field research in the Belgian Congo on behalf of the British Museum. See reproduction and photo in (Bettelheim and Berlo 2012, pp. 26-27). Bedia is an avid reader of anthropological literature but is keenly aware of anthropology's tangled and unethical history with colonization and empire building. "Mundele" is the word for white man in Kikongo, so the title in English is "White Man Wants to Know." There is a photo of Torday interviewing a Kuba elder from the first decade of the 20th century, where the elder seems to be turning away from Torday, who seems to be looking directly at a child to the right. To the left of the elder is a man who is also looking at the child, and behind the elder, there is another man who seems to be looking at the camera. Torday towers over the three men and the child (all sitting on the ground), with notebook and pen in hand. Bedia's painting incorporates the photo into the lower left corner; Bettelheim and Berlo claim that Bedia as a white Cuban is expressing his unease with his plight of wanting to know about Palo (and by extension indigenous cultures of the Americas, etc.), as well as concerns to avoid white paternalism and its link to colonialism and its history of physical and epistemic violence. However, in the case of Palo, Bedia sought out knowledge of the religion as a believer and became an initiate, as well as continuing to be a practicing palero. Palmié reminds us that when we use the term Afro-Cuban religions we are referring to its African ancestry not the ethnic or racial background of its believers, since many prominent santeros, babalaos, tata and yayi ngangas, and Abakuá are white.

Bedia's painting reproduces a large, stooped-over figure like in the photo, towering above a black, silhouetted figure on the floor, whose face is turned away from the "mundele" (white man). From the top of his head are two spiritual threads, if you will, that lead to two sitting figures almost identical but smaller. One of them is at the top of the painting and is upside down, the other lying on its side (on the right part of the frame). Now one can certainly read the white man in the painting as Bedia, in a kind of doubling effect of the photo. Perhaps Bedia is also one (or both) of the smaller figures coming out of the head of the larger seated figure. A quote from him (about the piece) would suggest just that, "That 
'necessary' black person that all Cubans have inside of us, that little black man defending us at the gate, the guardian, vigilant, alter ego from a true ancestor or not, but one that will be at the entry of every Cuban home, Ta José, Ta Francisco ... like the black man in the photograph, keeping guard over us wherever we are," in (Bettelheim and Berlo 2012, p. 26). To a degree, then, Bedia has reversed the terms of the photo; if one listens respectfully-and learns from the past - the path leads to spiritual knowledge not imperial domination.

The nganga is itself a unique spiritual object that both represents and speaks to (and from) the past. Aside from the obvious fact of the spirit of the dead (los muertos), there are the observations of scholars like Palmié and Routon who have analyzed the nganga and the relationship to its owner as strikingly similar to master-slave relationships in colonial times. The fact that the spirit must obey its owner certainly echoes those asymmetrical interactions that Palmié has described as based on "symbols of wage labor and payment, dominance and subalternity, enslavement, and revolt" (Palmié 2002, p. 167).

Slaves who were severely mistreated by their masters and had ngangas would use their prendas to punish their masters, fighting back against the extreme dehumanization of their plight. This reaction to the assault on their personhood reflected a confluence of religion, healing, and political revolt into which the ngangas were pressed into use, sometimes violently, as a kind of "healing by counter-attack" (Ibid., p. 178). Here, we see the mimicking of the plantation experience reversed. Palmié agrees with David Brown that there could be an alternative reading to the nganga. Brown suggests that the nganga "may be read not only as a miniature "forest" or "wilderness" ("monte," "manigua"), but as an analogue to the stockaded settlements ("palenques") of 19th century Cuban maroons. Viewed thusly, the fundamental ambiguity of the relationship between object (spirit/slave) and objectifier (priest/master) in modern Cuban practices appears in a different light: in keeping with the precarious nature of subjectivity in the ritual interactions with AfroCuban ngangas, the spiritual slave driver may well turn into a rebel captain, the symbolic plantation into a maroon camp" (Ibid., p. 184). Following both of these interpretations we can argue that depending on the circumstances, the nganga can function as symbolic plantation and maroon camp, as defender or aggressor, as healer or punisher. However, one must keep in mind that there are also cases where the "perro nganga" also turns on its owner. Routon tells the story of a palero named Salazar, whose reckless and alcoholic behavior led him to perform a "trabajo malo" (a negative spell) on a friend, who was subsequently killed in a bar fight. Salazar, stricken by guilt and grief, poured "chispa de tren" (a potent form of cane liquor) on his nganga-which he felt was the cause of his misfortune-and lit it on fire. Later that same day he tripped and fell and hit his head and died. The spirit in the nganga had revolted against its owner and retaliated (Routon, pp. 85-86).

Bedia's ngangas do not suggest the moral darkness of Salazar, and visually speaking, his representations of the prenda are remarkably "clean" and "orderly." When faced with real ngangas most people are confronted with an agglomeration of objects and elements that can seem baffling. Palmié reminds us of this confusion: "Visually, at least, for most non-practitioners of palo monte, a nganga suggests the violent, even sinister subversion of western conceptions of what kinds of substances and objects ought to be encountered in immediate proximity to each other. In Mary Douglas terms [purity and danger] it is an example of pollution raised to the status of method" (Palmié 2006, pp. 860-61). Bedia's art takes us through this seeming confusion by displaying the nature of the nganga, but he does not spoon feed us either. His work is not didactic, and we, as viewers, have to work a little (sometimes a lot!) to enter its realm, to understand it. However, at the same time, Bedia's work is direct, not obscure. Hernández again: "There is nothing, or very little that deliberately hampers interpretation. If [a specific work] is difficult and tortuous to read, indeed impenetrable for many, this is largely due to shortcomings in our information more than alleged perversities on behalf of the artist. I believe that Bedia even simplifies as much as he can at the moment of presenting his visual ideas" (Hernández, Op, cit., 122). Yet, the simplicity always carries a residue of enigma, of mystery. 
Such is the case with a piece titled "Ay Tata ¿hasta cuándo?" (1995; Oh Father, Until When?) See reproduction in (Pascual Castillo 2007, p. 37). The Tata referred to here is his mentor, his Tata-nganga, the Palo priest who initiated him. The title seems to be a rhetorical question about all the misfortune and illness in the world: how long will this madness go on? Below, the title is a large human figure in silhouette with a blue-aqua contour with a palo firma (signature) on the right side of his chest: it seems to signify Sarabanda, Bedia's mpungu, although there are firmas of Lucero or Elegguá that are similar. The circles represent the earth, the crosses the four cardinal points, the diagonal arrow that the firma is working for someone. The human figure says, "Cúbreme con tu manto, Baba" (Shield or protect me with your cloak, father). Here, the words seem to be addressed to Babalú Ayé (Ocha), known as San Lázaro in Catholicism. For paleros Babalú Ayé goes under many names: Pata Llaga, Matalá, Patipolo, Tata Pansua, Coballende, Mpungu Fútila, Nfumbe (Kimbisa), Pu Li La, Tata Kañengue, among others. Babalú Ayé is the orisha that lords over diseases-particularly smallpox and leprosy. In Cuba, both Lazarus the resurrected and Lazarus the beggar (with wounds on his knees, walking on crutches, and accompanied by a pair of dogs) form part of the worship of San Lázaro. Next to the large figure is a smaller one on crutches ascending a steep staircase, presumably San Lázaro, but without the dogs. The dogs appear on the large figure's thigh and back, one facing the viewer, the other on his back, in profile, looking toward the left. Below the dog is a church with two towers, the left has San Lázaro inscribed within it, the right one says Coballende (aka Kuballende, Cobayende). According to Ochoa, Coballende is an exalted figure for paleros since he is the only human to have returned to life, a true mediator between life and death. He is also depicted as a driver of a horse-drawn funerary cart (Ochoa 2010, pp. 282-83). Bedia's piece is a true summons to healing, while using the iconography and names of Catholic saints, Yoruba orishas, and Palo mpungus as a true crossroads not only of faiths, but of different and converging spiritual powers.

Babalú-Ayé (St. Lazarus) comes from three words: "baba," which means great father or ancestor; "olú," which means saint (or can also be used to designate the most knowledgeable amongst a group of babalaos); and "ayé" (veneration of ancestors, father of the poor). Like Bedia, who was inspired by Babalú-Ayé, the orisha looks to the past in that he is one of the three mpungus of the cemetery (along with Mariwanga Centello and Ma Kalunga), he looks to the side in helping and curing the sick, and he guarantees the future by strengthening the bond between the living and the dead.

The idea of crossroads is central to Afro-Cuban religious beliefs and is embodied by certain spiritual forces, known in Palo as Lucero Mundo or Nkuyu Nfinda. In Regla de Ocha, he is known as Elegguá (aka Esu, Eshu, Exu, Elegbara, Elegua, Legba, Eleda, Odara). Elegguá embodies the crossroads, the paths of life, the realm of fate. He is often referred to as trickster, is the messenger to the other spirits (or orishas), and is intimately tied to the divination process. John Mason offers an insightful view of his powers:

Esu is not just the guardian of vital life force but is synonymous with it. Elegbara can be thought of as the activator of DNA, which is made up of the four nucleotides, the four building blocks that are used to design everything in nature. Esu is the meeting point, the crossroads that put things together, and pull things together that are apart in opposition and seem not to agree ... Esu causes things and men to work together in harmony or suffer the consequence. He causes bees and men to swarm creating highly structured and complex social organizations. He is the cement that holds society together. Esu makes us realize our need for one another. Yet, Esu's sharply contrasting, provocative aloneness acts to promote our consciousness of the essentially solitary nature of humankind's existence. Birth, Life, and Death are solitary journeys despite our best efforts at amalgamation. The resulting consciousness heightens our awareness and fear of death and the other opponents of living beings, and prompts us to seek remedies to their destructive effects. (Mason 2003, p. 1) 
Bedia has a large piece titled "El señor de los caminos" (1996; Lord of the roads), done on acrylic and canvas. See reproduction in (Pascual Castillo 2007, pp. 62-63) It is fairly monochromatic, executed in a copper-hued brown, black, and white. It is a rectangular painting $(31 / 2 \mathrm{ft} . \times 9 \mathrm{ft})$, with a large figure emerging from the left side, presumably Elegguá himself taking a large stride with his left leg, with the foot resting on an anvil. His left arm is activating a bellows-like object that spews out smoke, echoing the cigar emitting smoke from Elegguá's mouth. The bellows covers part of what look like train tracks that are oval-shaped and extend over much of the surface of the painting. Within the oval train tracks there are another set of tracks that crisscross in the middle with a small "prenda" just above the cross, with palo "firmas" (signatures) on it. The firma is meant to relax and cool down a person. On the outer perimeter of the train tracks we see an automobile (far lower right), a tank on the bottom left but ascending and a locomotive with three cars moving along on the top left of the tracks.

Why the train tracks and train? Bedia is referencing Sarabanda again, his tutelary spirit. The anvil that the large figure steps on is associated with Sarabanda, as are the metal objects (railroad tracks, trains, cars, tanks) and also two knives, which are depicted in the inner part of the oval tracks. The knives are additionally symbolic of sacrifice, a further reminder of Elegguá's importance concerning all sacrificial rites of the religion. The nganga, true to form, also contains metal objects (a horseshoe and a blade).

Elegguá, or more accurately Lucero Mundo, has important ritual and symbolic functions in Palo. For example, many of the firmas are based on the Kongo cosmogram, showing a cross within a circle. In some ritual drawings, the circle is not overtly drawn but often suggested by the contour of the firma. The cardinal positions are symbols of spiritual power: north represents God or the awesome powers of creation, the south animals, the east plants and trees, and the west represents minerals; the four powers are known as the Four Winds (Martínez-Ruiz 2013, p. 73). For paleros, the lucero is the animating force of a prenda or nganga. Martínez Ruiz outlines this relationship:

In Palo Monte, the lucero is always used in practice in conjunction with a spiritual force. In Cuba each religious object (prenda) needs a lucero in order to function. It is the lucero that gives the spirit inhabiting the prenda the ability to travel and communicate with other forces and Palo practitioners. The lucero is described as the guiding light, the eyes of the prenda's spirit. To be guided in this way, all prendas must physically sit on a depiction of the lucero. (Ibid., p. 74)

In the painting Bedia depicts these guiding lights as star-like bursts or points of light, sometimes on bodies, other times on objects. Interestingly, the locomotive and cars of the train all have firmas on them, one meant to welcome a spirit, the other dealing with lightning and Mariwanga Centello (Oyá in Ocha), who rules over cemeteries.

Bedia skillfully combines Kongo graphic writing (firmas) with words (on the top, written in Spanish is "Señor de los caminos"), along with visual symbols (cars, humans, locomotives prendas, anvils), to create a powerful visual and spiritual tableau. Even the train tracks with the embedded cross ends up forming the infinity symbol, given further sustenance by the oval which is open-ended on the one hand, and augmented by the vastness and spareness of the background, on the other. In a way, the painting becomes a meta-lucero-signature, animating the nganga at the crossroads.

Bedia's paintings echo and recreate the nganga both as an "intricate ritual landscape" (Palmié 2006, p. 861), and as spiritual presence that emanates from the "muerto" as a powerful force that harnesses and interacts with a constructed microcosm of objects, liquids, earth, animals, bones, and blood. The nganga makes us question Western assumptions about drawing sharp distinctions between people and objects (Palmié 2006). What may seem inert becomes charged, imbued with a spiritual dynamism and an efficacy that reminds us of Thompson's "mpambu nzila," the crossing paths that elicit sacrifice and prayer and also knowledge, action, and transformation. Bedia's landscapes reveal the Sankofa (bird) in all us, looking back as it is propelled toward the future, dangling from and darting between the angels and demons of history. 
Funding: This research received no external funding.

Conflicts of Interest: The author declares no conflict of interest.

\section{References}

Bettelheim, Judith, and Janet Catherine Berlo. 2012. Transcultural Pilgrim, Three Decades of Work by José Bedia. Los Angeles: Fowler Museum at UCLA.

Cabrera, Lydia. 1992. El Monte. Miami: Ediciones Universal. First published 1954.

Hernández, Orlando. 2011. José Bedia, Escritos [Sobre], 1987-2010. Las Palmas: CAAM.

Martínez-Ruiz, Bárbaro. 2013. Kongo Graphic Writing and Other Narratives of the Sign. Philadelphia: Temple University Press.

Mason, John. 2003. Who's Knocking on My Floor? Esu Arts in the Americas. Brooklyn: Yoruba Theological Seminary.

Ochoa, Todd Ramón. 2010. Society of the Dead Quita Manaquita and Palo Praise in Cuba. Berkeley: University of California Press.

Palmié, Stephan. 2002. Wizards and Scientists, Explorations in Afro-Cuban Modernity and Tradition. Durham: Duke University Press.

Palmié, Stephan. 2006. Thinking with Ngangas: Reflections on Embodiment and the Limits of 'Objectively Necessary Appearances'. Comparative Studies in Society and History 48: 852-86. [CrossRef]

Pascual Castillo, Omar. 2007. José Bedia, Works, 1978-2006. Madrid: Ramis Barquet Gallery, Turner Libros.

Thompson, Robert Farris. 1993. Faces of the Gods. Munich: Prestel-Verlag.

Thompson, Robert Farris. 2011. Aesthetics of the Cool Afro-Atlantic Art and Music. New York: Prestel Publishing. 